\title{
Adjectives in Heritage Spanish ${ }^{1}$
}

\author{
Liliana Sánchez \\ University of Illinois Chicago \\ lesanch@uic.edu \\ José Camacho \\ University of Illinois Chicago \\ jcamach@uic.edu
}

Received: 29-12-20

Accepted: 03-02-21

Published: 26-02-21

How to cite: Sánchez, Liliana \& José Camacho. 2021. Adjectives in Heritage Spanish. Isogloss. Open Journal of Romance Linguistics 7, 3:1-20.

DOI: https://doi.org/10.5565/rev/isogloss.107

\section{Abstract}

Ordering of predicative adjectives within the Noun Phrase varies cross linguistically in systematic ways (Cinque 2010). In Spanish adjectival ordering exhibits more flexibility than in English. To test the extent to which the stricter word order in English affects Spanish adjectival ordering, 35 heritage bilingual Spanish speakers living in an English dominant environment were asked to judge adjectival word orders and interpret adjective elisions. Results indicate acceptance of adjectival ordering involving roll up movement (Cinque 2010), not possible in English. They also show the ability to interpret elisions in contexts involving the same type of movement. These results provide evidence for the availability of flexible ordering in Spanish even among Spanish-English bilinguals.

Keywords: adjectives; postnominal; heritage Spanish; stacking.

1 We would like to thank all participants in this study and Citlaly Herrera and Mariela Rodriguez for their assistance with data collection, as well two anonymous reviewers. 


\section{Table of Contents}

\section{Introduction}

2. The structure and interpretation of adjectives

3. The study
4. Results

5. Discussion and analysis

6. Final remarks References

\section{Introduction}

Predicative or extensional adjectives in most Romance languages have been shown to appear in post-nominal position (Bernstein 1991, 1993a,b, Bosque \& Picallo 1996, Picallo 2012, Zagona 2000, inter alia) and to be banned from prenominal positions, as shown in the contrast between (1) and (2):

$$
\begin{aligned}
& \text { Conozco un [río tranquilo] } \\
& \text { know.1.S a river quiet } \\
& \text { 'I know a quiet river.' } \\
& \text { (2) *Conozco un [tranquilo río] } \\
& \text { know.1.S a quiet river } \\
& \text { 'I know a quiet river.' }
\end{aligned}
$$

In addition to their post-nominal position, extensional adjectives exhibit strict ordering according to their meaning in languages such as English, as shown in (3) where an adjective of size precedes one of color and, in turn, this one precedes one of nationality:

$$
\text { A big blue Japanese vase }
$$

(English)

Cinque (2010) proposes that extensional adjectives exhibit a strict ordering related to the nature of their meaning (color, size, place of origin, among others), that due to NP-movement and XP movement appears to vary cross linguistically. Of the possible orders discussed by Cinque, only (4d) is not attested:

$$
\begin{aligned}
& \text { a. English, Chinese } \\
& A_{\text {size }}>A_{\text {color }}>A_{\text {nationality }}>N \\
& \text { b. Welsh, Irish } \\
& N>A_{\text {size }}>A_{\text {color }}>A_{\text {nationality }} \\
& \text { c. Indonesian, Yoruba } \\
& N>A_{\text {nationality }}>A_{\text {color }}>A_{\text {size }} \\
& \text { d. } * A_{\text {nationality }}>A_{\text {color }}>A_{\text {size }}>N
\end{aligned}
$$

In Spanish, predicative postnominal adjectives have been analyzed as adjuncts or specifiers (Bernstein 1991, 1993a, b, Bosque \& Picallo 1996) as a way to account for the possibility of recursion, as shown in (5):

(5) La bolsa blanca grande mexicana 
Their post-nominal position has been tied to the analysis of Nounmovement (Bernstein 1991), based on a parallelism with v-movement (Pollock 1989), but also to NP-movement (Lamarche 1989, Cinque 2010, Sánchez 1996, 2020 and others). Their ordering within the DP (Determiner Phrase) has been the subject of an analysis by Cinque (2010) in which so-called direct modifier adjectives occupy the specifier of a sequence of ordered projections, as shown in (6).

(6)

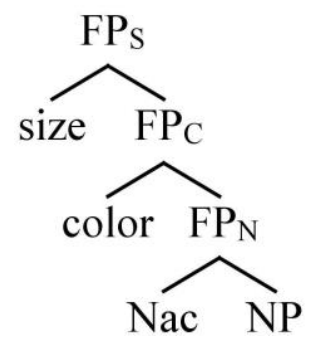

Additionally, since early work by Higgins (1973), 'attributive' adjectives have been equated to reduced clauses. Cinque (2010) notes the availability of a second source for adjectives as indirect modifiers, analyzed as reduced relative clauses, that makes it possible to alter the strict word order in (4). In the Italian example in (7), cinese, 'Chinese', is possible in last position because it is generated as a reduced relative clause, which merges higher than all the other adjectives.

(7) Un tavolo rotondo cinese

(Italian)

a table round Chinese

'A Chinese round table'

In Cinque's analysis, the availability of reduced clauses is limited in the sense that an indirect adjective introduced by them could not be closer to the noun than a direct one. Recursivity of predicative adjectives regardless of ordering, however, has been attested in Spanish and analyzed as the result of the availability of predicate structures within the DP (Sánchez 1996, 2020). The extent to which strict ordering of adjectives vs. recursive predicate adjective structures are both available in Spanish has been recently the object of corpus analysis (Perez Leroux et al. 2020) with evidence suggesting a preference for ordering but not to the exclusion of recursive predicative adjective structures. In that respect, Spanish appears to be a Romance language that allows both ordering and adjectival stacking without strict ordering in contrast with languages like English that exhibit less flexibility in the ordering of predicative adjectives.

In this study, we explore how heritage speakers of Spanish who live in an English dominant environment judge adjectival word orders and interpret examples in which some of the adjectives are elided. We hypothesize that because they live in an English dominant environment and have been more intensely exposed to English they might favor a stricter ordering of adjectives over predicate recursion in their judgments regardless of their level of proficiency in Spanish. We also test for the interpretation of expressions with elision of some adjectives as we expect, if one assumes a preference for strict ordering, some 
possibilities of elision would be ruled out and therefore not recoverable in the interpretation.

The paper has the following structure. In section 2 , we present an overview of Cinque's analysis (2010). In sections 3 and 4 we present the study and our findings, and in section 5 we discuss the results.

\section{The structure and interpretation of adjectives}

\subsection{Adjectival ordering}

Cinque (2010) observes that adjectival orderings can be derived from a universal hierarchy such as the one presented in (6). That hierarchy determines the default word order (size, color, nationality in English directly, as seen in (7a), whereas Spanish has the mirror image as unmarked, as seen in (7b).

$$
\begin{aligned}
& \text { a. The big blue Italian book } \\
& \text { b. El libro italiano azul enorme } \\
& \text { the book Italian blue big } \\
& \text { 'The big blue Italian book' }
\end{aligned}
$$

Cinque (2010) argues that an additional roll-up movement such as the one illustrated in (9) accounts for why the unmarked order in Romance-type languages is the mirror image order of (5). This kind of movement first merges the NP as a specifier of the first functional phrase $\left(\mathrm{FP}_{\mathrm{N}}\right), \mathrm{FP}_{\mathrm{N}}$ then merges as a specifier of the immediate functional phrase $\left(\mathrm{FP}_{\mathrm{C}}\right)$ and so on.

(9)

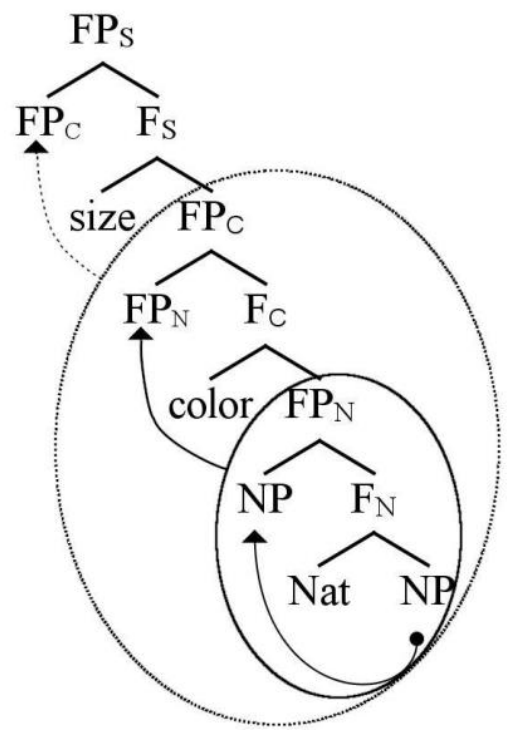

The combination of roll-up movement and the additional reduced-relative clause position predicts a wide array of marked word orders, although those are not always attested. Nationality adjectives, for example, must be adjacent to the NP in English. When they are not, the result is ungrammatical, as shown by the ungrammatical orders in (10a) and (10b) (from Cinque 2010). Following the logic of Cinque's analysis, (10) is ungrammatical because it cannot be directly 
generated by the hierarchy in (6), and no alternative reduced-relative clause source is available for Italian as an indirect modifier. In other words, nationality adjectives cannot be generated as reduced-relative clauses in the context of (9).

(10) a. *An Italian big yellow book

b. *An Italian yellow big book

Cinque's (2010) proposal has interesting implications for bilingual speakers whose languages have the English-type and the Romance-type patterns. As described above, the default Romance-type order in (11a) is derived from the base order in (6) with subsequent roll-up movement (see 9).

(11) a. Un libro italiano verde grande

(NCS, Spanish)

a book Italian green big

b. Un libro grande verde italiano

(SCN, Spanish)

a book big green Italian

c. Un libro verde grande italiano

(CSN, Spanish)

a book big Italian green

A big, green Italian book

The adjectival order in (11b) corresponds to the base order in (6), the default one for English, with the additional movement of the NP passed the adjectives, as shown schematically in (12). We take this NP movement to be an independent kind from roll-up, in the sense that certain languages like Welsh (cf. (4) above and Cinque 2010) have NP movement but no roll-up. Taking all of this into account, if heritage Spanish speakers accept the order in (11b), it may show crosslinguistic influence from English in lacking roll-up movement despite exhibiting NP movement.

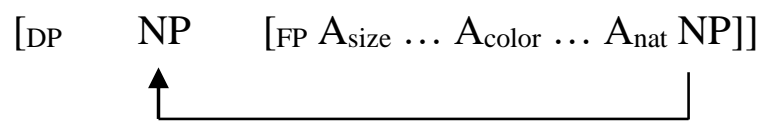

$(\mathrm{NP}>\mathrm{S}>\mathrm{C}>\mathrm{N})$

The order in (11c), on the other hand, is more complex. Since verde 'green' precedes grande 'big', that order deviates from the hierarchy in (6). Rollup movement does not generate that order by itself either, because after strict rollup, italiano 'Italian' should be adjacent to the NP, as in (8) or as in (11a). The only possible derivation for (11c) is therefore to assume that italiano is an indirect modifier in the higher reduced-relative clause position and that libro verde has rolled up above grande, as seen in (13).

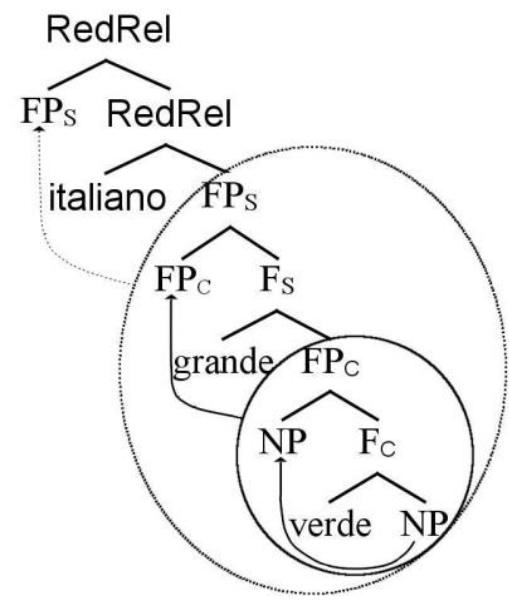


Notice that the derivation in (13) is not compatible with English grammar for two reasons: English does not have roll-up, and as we saw in (10), nationality adjectives are not possible as reduced-relative clauses.

In sum, comparing (11b) to (11c), the acceptability of (11b) would be more compatible with the grammar of English, and therefore with crosslinguistic influence from English, whereas the acceptability of (11c) would be incompatible with the grammar of English. As a consequence, we propose the first research question in (14).

(14) Research Question 1:

Do heritage speakers have a higher level of acceptance of the order NP $>\mathrm{S}$ $>\mathrm{C}>\mathrm{N}(11 \mathrm{~b})$ than of the orders $\mathrm{NP}>\mathrm{N}>\mathrm{S}>\mathrm{C}(10 \mathrm{a})$ and $\mathrm{NP}>\mathrm{C}>\mathrm{S}>$ $\mathrm{N}(10 \mathrm{c})$ ?

Hypothesis 1:

We hypothesize that the English-compatible adjectival order (SCN) would be preferred by HSs at lower levels of proficiency, under that assumption that they may experience cross-linguistic influence from English.

In the next subsection we present our assumptions on ellipsis and our second research question.

\subsection{Adjectival order interpretation in ellipsis}

Given the relative flexibility of adjectival word orders discussed in the preceding section, an open question remains as to how speakers interpret stacked adjectives. Ellipsis allows us to test the word order of DPs. DP-internal ellipsis in Spanish can appear with the morpheme $-o /-a$ as a referring to the elided constituent, as seen in (15), and the ellipsis in the second conjunct can be interpreted as una casa pequeña a small house or as una casa alemana pequeña a small German house.

$$
\begin{aligned}
& \text { [Un-a cas-a aleman-a grande] y [un-a pequeñ-a] } \\
& \text { a-F house-F German-F big and a-F small-F } \\
& \text { 'A big German house and a small one' }
\end{aligned}
$$

(Spanish)

The long tradition of research into NP-ellipsis in Spanish does not have a clear answer to how the second conjunct is interpreted (cf. Brucart 1987, Bernstein 1993, Lobeck 1995, Kornfeld \& Saab 2005, Ticio 2010, Saab 2010, among many others, see Ticio 2016 for a summary). The literature tends to assume that only NP nodes can be elided (cf. Ticio 2010), but exactly what that covers depends on the internal structure of DPs. Ticio (2010), for example, assumes that prenominal adjectives are dominated by NP, so they must be elided, but postnominal adjectives may survive the ellipsis because they are not dominated by NP. Cinque's (2010) proposal questions this underlying asymmetry between prenominal and postnominal adjectives, and the structural distinction between direct and indirect modification further complicates how the target of the elision is interpreted. Assuming that postnominal adjectives can be elided with the NP, the interpretative patterns can illuminate the internal structure of adjective 
orders in the DP. In the case of heritage speakers of Spanish, the possibility of recovering the ellipsis in a structure such as (15) with the order NSC and involving two a roll up movement (FP1 to spec of FP2) would be revealing of strength in the availability of the Spanish representation, especially given the impossibility of roll-up movements in English.

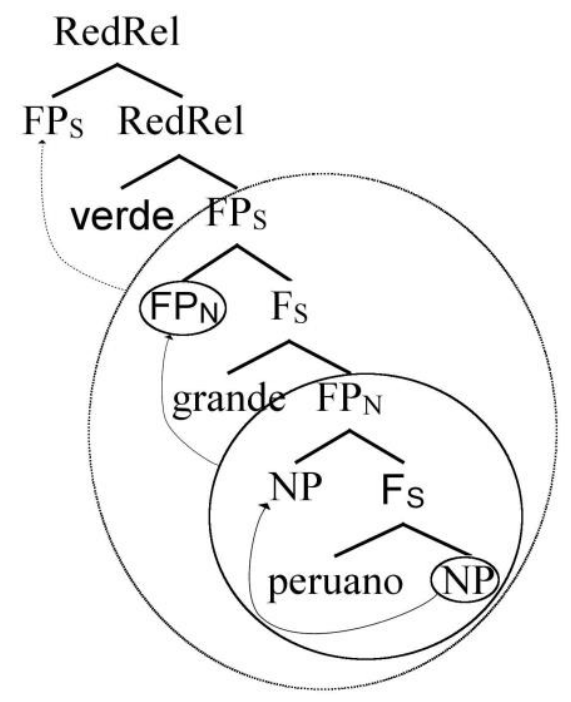

Based on this idea, the second research question is presented in (17).

(17) Research Question 2:

How do heritage speakers interpret stacked adjectives in cases of ellipsis?

Hypothesis 2:

We hypothesize that HSs with a strong representation of Spanish roll up movement should be able to interpret the ellipsis of nationality and size in the order $\mathrm{N}>\mathrm{S}>\mathrm{C}$. The unavailability of this interpretation could be suggestive of crosslinguistic influence from English.

\subsection{Adjectival ordering in second language and heritage Spanish}

In this section, we present previous studies on adjectives in bilingual Spanish. Most of the previous work on ordering within the DP in bilingual grammars focuses on prenominal vs. postnominal adjectives (cf. Parodi, Schwartz, \& Clahsen 2004, originally circulated in 1997, Gess \& Herschensohn 2001 and Bruhn de Garavito \& White 2002).

Anderson's $(2001,2008)$ research is the first to study the interaction between adjective position and semantic interpretation, specifically intersective vs. non-intersective interpretations. His results show that second language (L2) learners established both the word-order pattern and the interpretive distinctions associated with the word-order differences. Androutsopoulou, Español-Echevarría \& Prévost (2008) extends this paradigm to the acquisition of evaluative adjectives (good, nice, etc.) by L1-French/L2-Spanish learners, concluding that intermediate-level L2 Spanish learners have difficulty acquiring prenominal adjective orders, whereas advanced learners, on the other hand, fall back onto L1 
patterns. In general, they find that learners also showed different sensitivities to different adjective-types.

Rothman, Judy, Guijarro-Fuentes \& Pires (2010) studied L1-English/L2Spanish bilinguals and found target-like acquisition of adjective word order and the associated meaning distinctions among advanced learners and a subgroup of intermediate learners. Another subgroup had results closer to chance.

Finally, Camacho (2018) focused on heritage speakers of Spanish who are bilinguals living in an English dominant environment. Heritage speakers of Spanish in the US are exposed to Spanish as a home language and in the course of their lives, experience a shift in dominance from their home language to the socially dominant language (Valdés 2000, Montrul 2011, Kupisch and Rothman 2018). He found monolingual-like patterns of adjectival placement (N-Adj), taking into account the fact that the same adjective can be interpreted differently depending on the position. The intermediate-level group had slightly higher ratings for Adj-N than monolinguals, whereas the lower proficiency group did not show a clear preference for post nominal adjectives. Assuming Cinque's (2010) analysis of a common underlying order for Spanish and English adjectives, with NP-raising in Spanish, Camacho argues that the higher and intermediate proficiency groups' show NP movement with deletion of the lower copy. For the lower proficiency group, this study argued for two possibilities: either the NP does not raise, just as in English, or the NP does raise, deleting the higher copy. Deleting the higher copy makes the linear sequence Adj>NP compatible with that of English, while still preserving the structural properties of the other grammar, which has NP-raising.

In sum, previous research on the bilingual acquisition of adjectival order suggests that intermediate and advanced level speakers show word order and semantic restrictions similar to monolinguals, whereas lower-level speakers do not. The proposed account for those cases involves either lack of NP raising due to crosslinguistic influence from English, or raising and deletion of the higher copy, as a form of linear convergence between English and Spanish. In this study, we explore the extent to which there is any sort of convergence with English among heritage speakers of Spanish regarding adjectival word order.

\section{The Study}

In order to test the hypotheses presented in (14) and (17), we designed a study on the representation of adjectival word order among heritage speakers of Spanish living in the United States. We decided to investigate the extent to which exposure to English could affect adjectival ordering in the Spanish of heritage speakers. As it has been shown in the past, heritage speakers show differential access to representations in productive and receptive tasks (Perez Cortés et al. 2019, Putnam \& Sánchez 2013) and their results in those tasks may also be affected by their level of proficiency (Wiener \& Tokowicz 2019). In order to cover both productive and receptive data as well as a measure of proficiency, the study included four parts: a linguistic background questionnaire, a proficiency task, an acceptability judgment task, and an interpretive task presented using Qualtrics software (Qualtrics, Provo, UT). 


\subsection{Participants}

A total of 35 participants between 18 and 27 (mean age $=21.8$ ) were recruited in Illinois and Virginia for this study, 25 females, 9 males, and one did not answer about their gender.

Based on the results of the Bilingual Language Profile (Gertken et al. 2014, see below), we determined that thirty-two of the participants qualified as heritage speakers, since they reported learning Spanish from birth, one at age 1, one at age 3, and one at age 4. Regarding the onset of English, 9 participants reported beginning to learn it by age 2,11 by age 3,14 between ages 4 and 6 , and 1 at age 10. All the participants reported that their family spoke Spanish, and 27 reported that no English was spoken in their family.

All the participants had completed high school, 19 were studying at a US college, 8 had completed college, and five were in graduate school at the time of the survey. We calculated the time spent in formal education in each language as a percentage of their age, and the average for Spanish was 22\% (SD =18) and 72\% $(\mathrm{SD}=18)$ for English. In other words, these speakers have been educated mostly in English.

Participants showed positive attitudes towards English and Spanish: they feel more like themselves in English (5.8 vs. 4.8 on a scale of 0-6), but they identify with Spanish-speaking culture more (5.2) than with an English-speaking culture (3.3).

While we do not know the precise dialectal background of their families, anecdotal evidence suggests most of them were from Mexican communities in New Jersey and Chicago. ${ }^{2}$

\subsection{Tasks}

The Bilingual Language Profile (Gertken et al. 2014) questionnaire was administered as a linguistic background questionnaire. The Spanish proficiency task, first used in Duffield \& White (1999), incorporated sections from standardized Spanish as a second language proficiency tests, namely the reading/ vocabulary section of the MLA Cooperative Foreign Language Test (Educational Testing Service, Princeton, NJ) and a cloze test from the Diploma de Español como Lengua Extranjera (DELE) (Embajada de España, Washington, DC). It consisted of 30 multiple choice answers and 20 cloze questions that were randomized.

\subsubsection{Acceptability judgment task}

Participants were told that they should help different people who are learning Spanish by determining which sentences are more acceptable in the given context. Please rank each sentence on a scale from 1-5 (1=not acceptable, 5=acceptable). This instruction was also given in Spanish. The experimental items consisted of nominal structures with a $\mathrm{N}$ followed by three adjectives in three word orders, as seen in (18). Each word order type had three tokens with a total of 9 experimental items.

2 We do not have information on other languages they may speak, particularly native languages of Mexico, although it is very likely that if they have had exposure to a native language, it will be limited, given the social difficulties of maintaining those languages even within the home in the US. 
(18) a. Un libro inglés grande azul $\left(\mathrm{N}>\mathrm{A}_{\text {nationality }}>\mathrm{A}_{\text {size }}>\mathrm{A}_{\text {color }}\right.$, Spanish) a book English big blue

A big, blue English book

b. Un libro grande azul inglés $\quad\left(\mathrm{N}>\mathrm{A}_{\text {size }}>\mathrm{A}_{\text {color }}>\mathrm{A}_{\text {nationality }}\right.$, Spanish $)$ a book big blue English

'A big, blue English book'

c. Un libro azul grande inglés $\left(\mathrm{N}>\mathrm{A}_{\text {color }}>\mathrm{A}_{\text {size }}>\mathrm{A}_{\text {nationality }}, \mathrm{Spanish}\right)$ a book blue big English

'A big, blue English book'

All three orders require a reduced-relative clause source for the last adjective, and only (18b) is compatible with the adjectival word order in English, as discussed in section 2.1. Therefore, crosslinguistic influence from English should improve ratings for (18b) vs. (18a) and (18c).

In addition to the experimental items, the task included five control items, one declarative sentence with SVO order, one with VO, one with $\mathrm{SV}_{\text {nonFin }} \mathrm{O}$, one $\mathrm{V}_{\text {nonFin }} \mathrm{SO}$, and a VSO question.

\subsubsection{Interpretation task}

This task assessed how participants interpret phrases in which one or more adjectives are elided. For example, in the experimental item presented in (19), participants first read a short context that introduced the noun and the three adjectives in separate phrases, followed by a target sentence of the form me compré un cuadro peruano, grande y rojo y uno verde I bought a red, big, Peruvian painting and a green one. Finally, participants were asked to choose how the second item was among three possible answers, one with three adjectives, one with two or one with the single adjective explicitly present in the target sentence.

(19) Context: María fue de viaje a Perú y se compró un cuadro típico del tamaño más grande que había y de su color preferido que es el rojo. Cuando regresó le contó a su novio.

'Maria travelled to Peru and bought a painting of the biggest kind that there was, and of her preferred color, which is red. When she returned, she told her boyfriend.'

Target sentence: Me compré un cuadro peruano grande rojo y

CL bought a painting Peruvian big red and uno verde.

(Spanish)

one green

'I bought a big, red, Peruvian painting and a green one'

Interpretation: ¿Cómo era el segundo cuadro?

How was the second painting?

Choices:
a) Peruano, grande y verde
Big, green, and Peruvian
b) Peruano y verde
c) Verde
Peruvian and green
Green 
Assuming that the elided site forms a single constituent (represented by $e$ in 20), answer a) suggests that cuadro peruano grande forms a single constituent, as in (20a), answer b), suggests the constituent cuadro peruano as in (20b) and answer c), suggests only the NP, as in (20c).

$$
\begin{array}{lll}
\text { a. } & {[\text { uno }[e] \text { verde }]} & e=\text { cuadro peruano grande } \\
\text { b. } & {[\text { uno }[e] \text { verde }]} & e=\text { cuadro peruano } \\
\text { c. } & {[\text { uno }[e] \text { verde }]} & e=\text { cuadro }
\end{array}
$$

Given the word order of the target sentence and the possible answers, if we assume crosslinguistic influence from English, option a should be the least preferred interpretation as it involves roll up movement.

Six tokens with different adjectives and nouns were included and 5 control items such as the one illustrated in (21).

(21) Roberto fue al mercado y se compró fruta, carne y verduras. Cuando regresó le contó a su esposa.

'Roberto went to the market and bought fruit, meat and vegetables. When he returned, he told his wife.'

-Me compré fruta, carne, y verduras.

'I bought fruit, meat and vegetables'

-¿Cuál era la segunda cosa que se compró Roberto?

'What was the second thing that Roberto bought?'
a) carne
meat
b) fruta
fruit
c) verduras
vegetables

\section{Results}

\subsection{Proficiency task}

Participant scores on the Spanish proficiency test are presented in Figure 1, with a mean score of 74.6\% (Min: 40, Max: 92, SD: 11.61). Additionally, as Figure 2 shows, proficiency scores were moderately, but significantly correlated with the self-rating score, composed of the sum of reading, understanding and speaking ratings $(r(33)=.46(\mathrm{p}=.005)$. 
Figure 1. Scores in the Spanish proficiency task

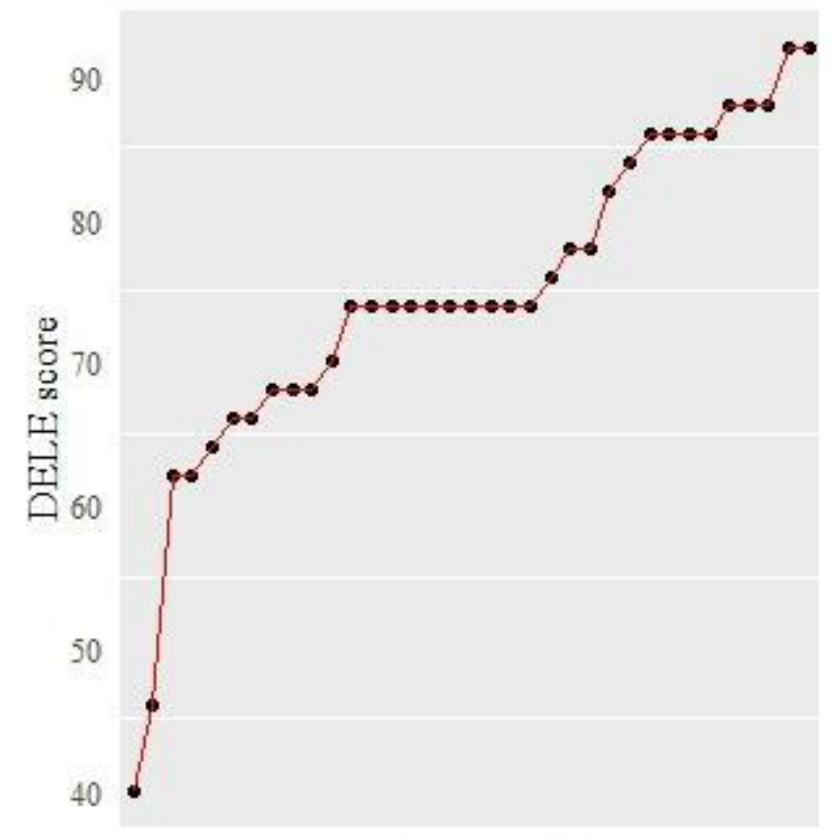

Participant

Figure 2. Correlation between self-rating and proficiency

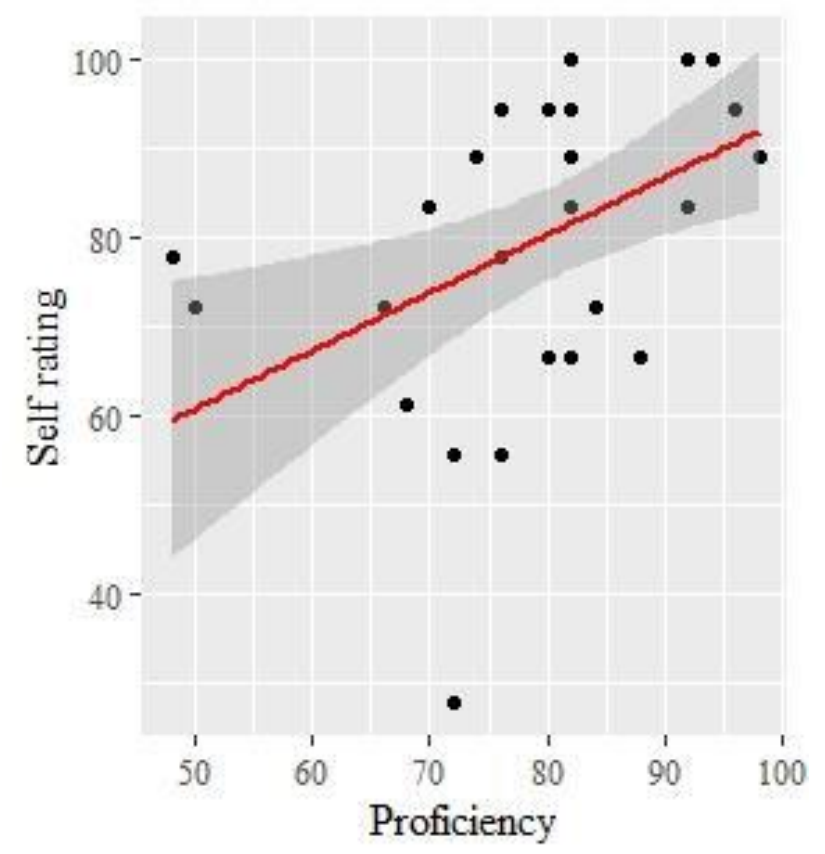

Figure 3 shows that participants rated experimental conditions lower than the two (S) VO items, and this difference was statistically significantly different $(\mathrm{t}=-6.0$, $\mathrm{df}=66.6, \mathrm{p}<0.001)$. 
Figure 3. Mean rating for experimental and control conditions by participant

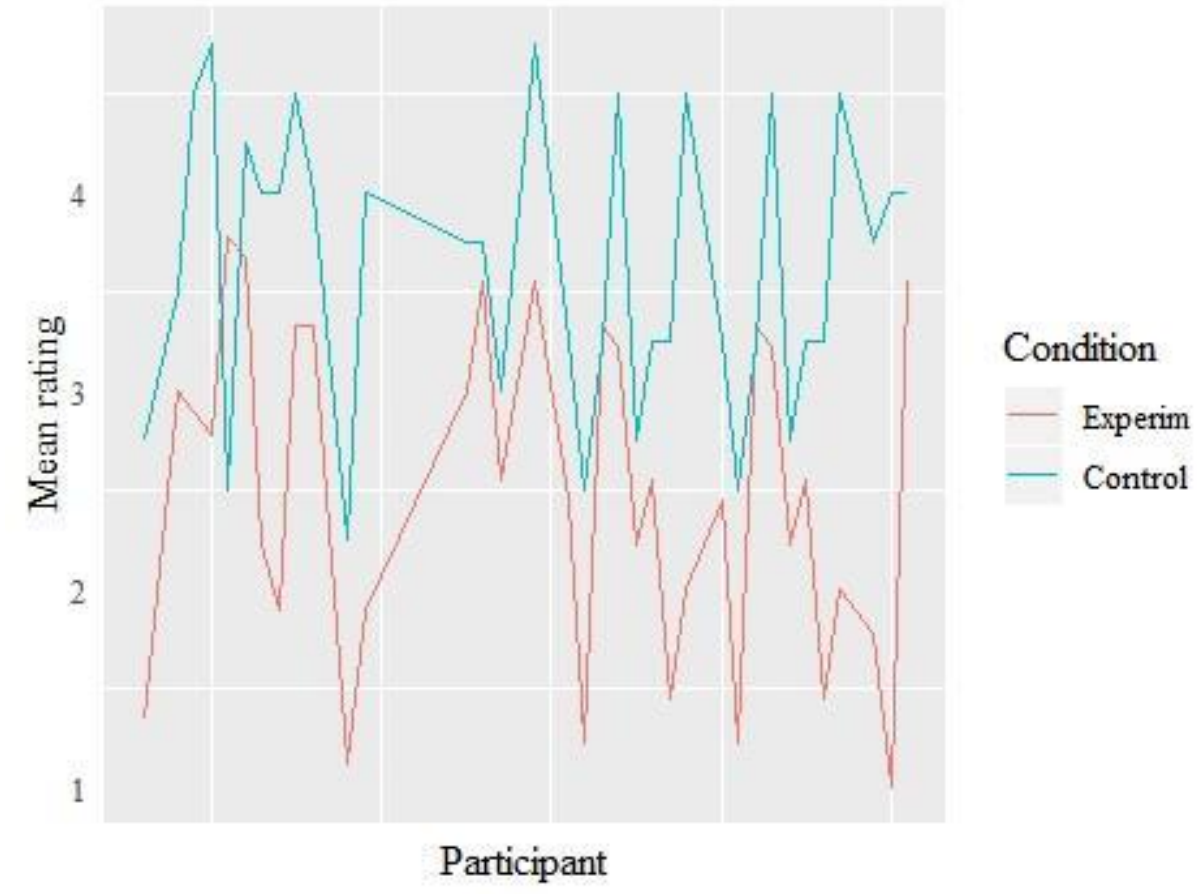

These results show that participants had greater command of the control items, as expected.

\subsection{Results from the AJT task}

We explored whether participants reacted differently to items depending on the order of the adjectives. As noted in section 2.1, we expected the order SCN to be preferred over NSC and CSN, since the last two orders are incompatible with the English adjectives order. We fit a linear regression ( $\mathrm{R}, \mathrm{lme} 4)$ with ratings as the dependent variable and word order (NSC, SCN, CSN) as independent variables. The results in Table 1 show that none of the word orders had a significantly different effect on rating. Compared to Nationality > Size > Color, participants rated CSN 0.33 points lower, and SCN .17 points lower. Overall, the model fit was very low $\left(\mathrm{R}^{2}=0.01\right)$

Table 1. Linear regression results for ratings as a function of word order

\begin{tabular}{|c|c|c|c|c|}
\hline & Estimate & SE & t value & $\operatorname{Pr}(>|\mathbf{t}|)$ \\
\hline (intercept) & 2.657 & 0.129 & 20.566 & $<.0001$ \\
\hline CSN & -0.333 & 0.182 & -1.824 & 0.069 \\
\hline SCN & -0.171 & 0.182 & -0.938 & 0.349 \\
\hline
\end{tabular}

Additionally, we explored whether the continuous variable proficiency may have an effect on ratings depending on word order. The resulting linear regression results seen in Table 2 and represented in Figure 4, suggest that ratings decrease with proficiency, although very slightly. Proficiency and word order 
interactions were not significant and did not improve the overall model. Overall, the model fit was very low $\left(R^{2}=0.02\right)$.

Table 2. Linear regression results for ratings as a function of word order and proficiency

\begin{tabular}{|c|c|c|c|c|}
\hline & Estimate & $\mathbf{S E}$ & $\mathbf{t}$ value & $\operatorname{Pr}(>|\mathbf{t}|)$ \\
\hline (Intercept) & 3.638 & 0.53 & 6.865 & $<0.0001$ \\
\hline CSN & -0.333 & 0.181 & -1.832 & 0.067 \\
\hline SCN & -0.171 & 0.181 & -0.942 & 0.346 \\
\hline Proficiency & -0.012 & 0.006 & -1.909 & 0.05 \\
\hline
\end{tabular}

To the extent that ratings for SCN were not significantly higher than ratings for the other two orders, we did not find evidence for $\mathrm{H} 1$ given that NSC and CSN had similar rates of acceptance regardless of proficiency in the Spanish of the participants in the study.

Figure 4. Ratings by proficiency for the different word orders

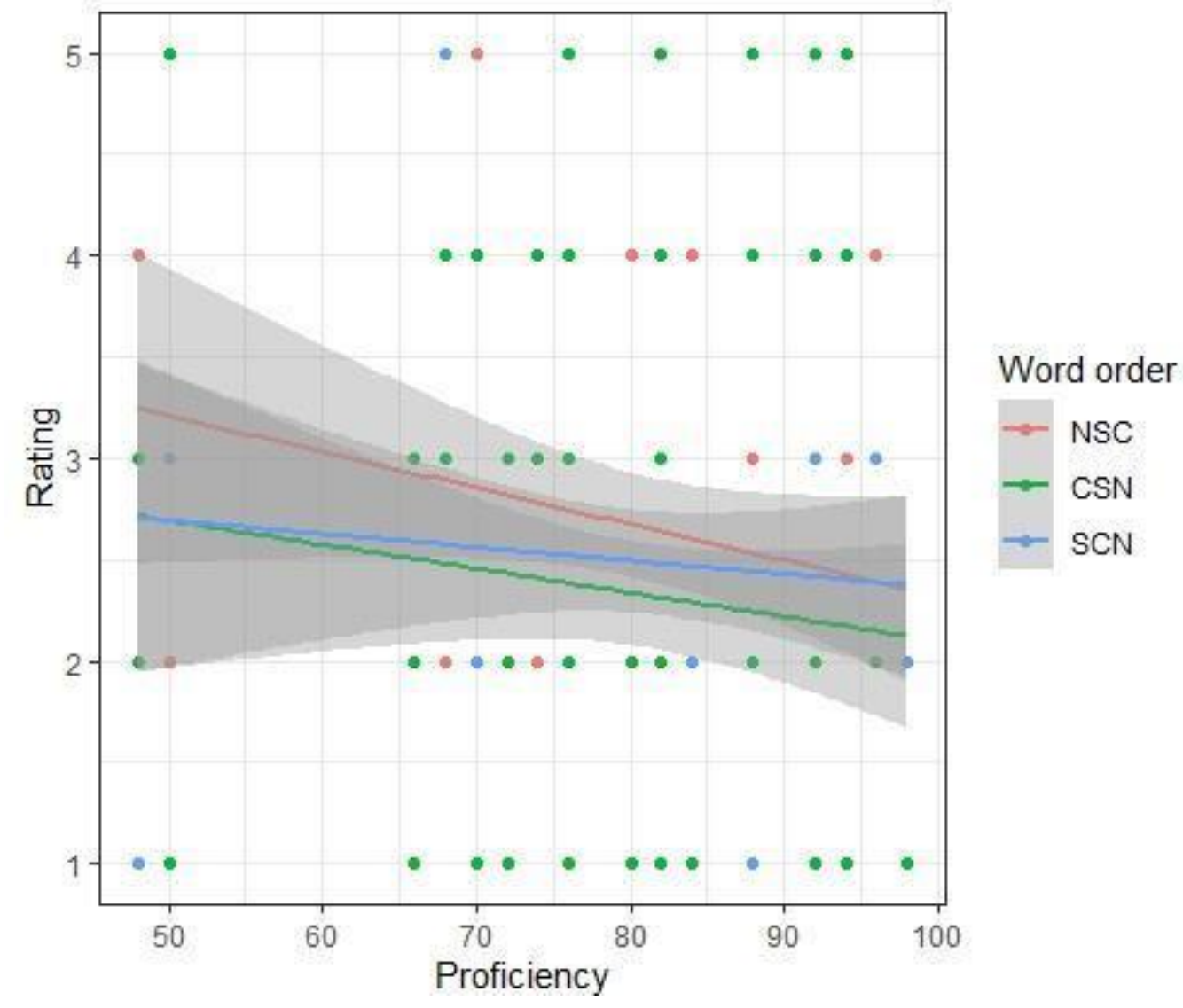

However, we do notice that as proficiency levels increase, ratings for all three orders decrease, as expected, since these are marked orders. The reduction in SCN is less steep, which would be consistent with English crosslinguistic influence, if the trend had been significative. 


\subsection{Results for interpretive task}

As mentioned above, participants were expected to select the interpretation of elided material in a conjunction, with one, two or three adjectives. In order to compare results, we coded answers as selecting one (color), two (nationality and color) or three adjectives (nationality, size and color), as seen in Table 3. Participants chose the nationality + size + color option almost half of the time $(44 \%)$, followed by the single color adjective $(39.5 \%)$ and the nationality + color adjective combination $(16.5 \%)$. The difference between the choices was statistically significantly different $\left(\chi^{2}=21.65, \mathrm{df}(2), \mathrm{p}<0.001\right)$.

Table 3. Frequency of choice, interpretive task

\begin{tabular}{|c|c|c|c|}
\hline Color & $\begin{array}{c}\text { Nationality }+ \\
\text { Color }\end{array}$ & $\begin{array}{c}\text { Nationality }+ \\
\text { Size + Color }\end{array}$ & Total \\
\hline 69 & 29 & 77 & 175 \\
$39.5 \%$ & $16.5 \%$ & $44 \%$ & $100 \%$ \\
\hline
\end{tabular}

These results provide support for $\mathrm{H} 2$, which predicted that HSs with a strong representation of NSC order should be able to interpret the elision of nationality and color involving roll up movement. Of interest is that participants preferred color over nationality and color, a preference we discuss below.

\section{Discussion and analysis}

The results from the acceptability judgement task show that heritage speakers accept the three possible word orders. This pattern of acceptance suggests that they apply the roll-up merger and that they accept the reduced-relative clause position for nationality adjectives. These are the two properties that distinguish Spanish from English, as we discussed. Although proficiency does not seem to be a determining factor in the preference for word order, the data suggest an increasing sensibility to the marked nature of the word orders we tested. Finally, the relatively higher stability of the order SCN as proficiency increases can be interpreted as a subtle cross linguistic effect from English, since this option is consistent with the direct modifier order for adjectives in English.

Having shown that the participants in this study accept multiple word orders, we can now address the results of the interpretation task. As suggested, Cinque's analysis does not directly predict a preference for one or the other options, assuming that the ellipsis site can include one or two adjectives. The option with the highest preference was to interpret the elided site as involving two adjectives, nationality + size (recall that the elided conjunct already contained an overt color adjective). Structurally, this option interprets the elision as involving the lower functional projections, as shown with a circle and before roll up movement in (22). As (16) above shows, the order cuadro peruano grande 'big Peruvian painting' results from NP movement to the spec of the lowest FP and roll up movement involving Peruvian and big. The order cuadro peruano grande verde results from verde as a reduced clause. 


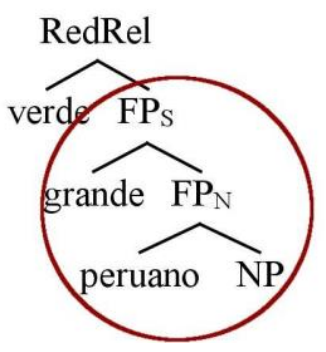

We take the preferred interpretation (nationality + size) to indicate the recovery of the rolled-up constituent which is consistent with the acceptability of NSC in the first task. The second preferred choice (verde green) targets just the NP, as in (23).

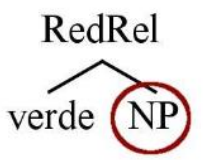

This is a possible interpretation but is clearly less informative and it seems to indicate that the nationality + size constituent is not recovered or not taken into account when processing the ellipsis.

The third option, nationality + color, requires targeting a node that includes an indirect modifier, generated as a reduced-relative clause, and a direct adjective, generated low, avoiding the intermediate direct modifier grande big. Assuming that ellipsis sites are single constituents, one expects this option to be fairly marked.

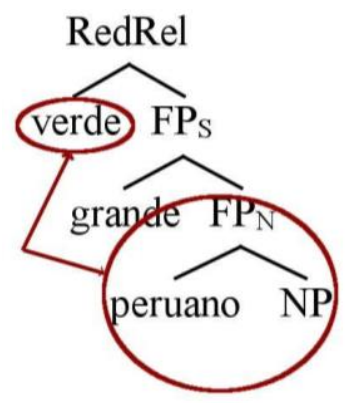

Its lower levels of acceptance are consistent with the fact that the majority of the speakers in this sample are above $70 \%$ in the proficiency task. The robust nature of the judgements on Spanish adjective orderings suggests that at least for this sample no convergence in linear ordering is taking place unlike in the previous study by Camacho (2018).

Overall, both the results of the acceptability task and the interpretation task point in the direction of strong Spanish representations in the majority of speakers in this sample. Of course, we acknowledge that our sample has more participants whose results are above 50\% than participants at or below 50\% in the proficiency task. This distribution may bias the results by showing strong Spanish representations and lower levels of crosslinguistic influence. In that respect, the support we found for our first hypothesis is tentative. A replication of this study 
with more participants at lower levels of proficiency would be required to establish the extent to which proficiency interacts with word order preference and interpretation among Heritage Speakers of Spanish with a wider range of proficiency levels. However, regarding the second hypothesis, our results do point out that in a sample with proficiency levels above $60 \%$ for the majority of participants (33 out of 35), 44\% of the time participants showed a preference for an interpretation that matched a word order deemed acceptable in Spanish. We acknowledge that further research is needed to explore in more depth the extent to which this interpretation is readily available to heritage speakers at lower levels of proficiency.

\section{Final remarks}

In this paper we explored the availability of different possible adjective orderings among Heritage Spanish speakers with different levels of compatibility with English adjective orderings. Results of an acceptability judgement task and an interpretation task with elisions suggest that among the heritage speakers in our sample representations incompatible with English are acceptable and that elision with roll up movement is recoverable in interpretation. Proficiency in Spanish was not found to be a factor in guiding preference for the different orderings but further studies are needed with populations at lower levels of Spanish proficiency.

\section{References}

Anderson, Bruce. 2001. Adjective position and interpretation in L2 French. In J. Camps \& Caroline Wiltshire (eds.), Romance Syntax, Semantics and their L2 Acquisition, 27-46. Amsterdam: John Benjamins. https://doi.org/10.1075/cilt.216.05and

Anderson, Bruce. 2008. Forms of evidence and grammatical development in the acquisition of adjective position in L2 French. Studies in Second Language Acquisition 30: 1-29. https://doi.org/10.1017/S0272263108080017

Androutsopoulou, Antonia, Español-Echevarría, Manuel \& Prévost, Philippe. 2008. On the acquisition of the prenominal placement of evaluative adjectives in L2 Spanish. In J. Bruhn de Garavito \& E. Valenzuela (eds.), Selected proceedings of the 10th Hispanic Linguistics Symposium. 1-12. Somerville, MA: Cascadilla Proceedings Project.

Bernstein, Judy. 1991. DP'S in French and Walloon: Evidence for parametric variation In nominal head movement. Probus 3: 101-126. https://doi.org/10.1515/prbs.1991.3.2.101

Bernstein, Judy. 1993a. Topics in the syntax of nominal structure across Romance. Ph.D. dissertation, City University of New York, New York, NY, USA.

Bernstein, Judy. 1993b. The syntactic role of word markers in null nominal constructions. Probus 5: 5-38. https://doi.org/10.1515/prbs.1993.5.1-2.5 
Bosque, Ignacio \& Picallo, Carme. 1996. Postnominal adjectives in Spanish DPs. Journal of Linguistics, 32: 349-385. https://doi.org/10.1017/s0022226700015929

Brucart, José María. 1987. La elisión en español. Doctoral dissertation, Universidad Autònoma de Barcelona.

Bruhn de Garavito, Joyce \& Lydia White. 2002. L2 acquisition of Spanish DPs: the status of grammatical features. In A. T. Pérez-Leroux \& J. Liceras (eds.), The acquisition of Spanish morphosyntax: The L1/L2 connection. 153-178. New York: Springer. https://doi.org/10.1007/978-94-010-0291$\underline{2 \_} 6$

Camacho, José. 2018. The interpretation of adjective-N sequences in Spanish heritage. Languages 3: 46, https://doi.org/10.3390/languages3040046

Cinque, Guglielmo. 2010. The Syntax of Adjectives. Cambridge, MA: MIT Press.

Duffield, Nigel \& White, Lydia. 1999. Assessing L2 knowledge of Spanish clitic placement: Converging methodologies. Second Language Research, 15: 133-160, https://doi.org/10.1191/026765899668237583

Gess, Randall \& Julia Herschensohn. 2001. Shifting the DP parameter: A study of anglophone French L2ers. In Joaquim Camps \& Wiltshire, Caroline (eds.), Romance syntax, semantics and their L2 acquisition. 105-119. Amsterdam: John Benjamins. https://doi.org/10.1075/cilt.216.10ges

Gertken, Libby M., Amengual, Mark, \& Birdsong, David. 2014. Assessing language dominance with the bilingual language profile. In P. Leclercq, A. Edmonds \& H. Hilton (eds.), Measuring L2 proficiency. Perspectives from SLA. 208-225. Bristol: Multilingual Matters. https://doi.org/10.21832/9781783092291-014

Higgins, F. Roger. 1973. The pseudo-cleft construction in English. Ph.D. thesis, Massachusetts Institute of Technology.

Kornfeld, Laura \& Saab, Andrés. 2004. Nominal ellipsis and morphological structure in Spanish. In R. Bok-Bennema, B. Hollebrandse, B. KampersManhe \& P. Sleeman (eds.), Romance languages and linguistic theory 2002: Selected papers from 'Going Romance', Groningen, 28-30 November 2002. 183-199. Amsterdam: John Benjamins. https://doi.org/10.1075/cilt.256.11kor

Kupisch, Tanja, \& Rothman, Jason. 2018. Terminology matters! Why difference is not incompleteness and how early child bilinguals are heritage speakers. International Journal of Bilingualism, 22: 564-582. https://doi.org/10.1177/1367006916654355

Lamarche, Jacques. 1991. Problems for $\mathrm{N}^{\circ}$-Movement to Num-P. Probus, 33: 215-236. https://doi.org/10.1515/prbs.1991.3.2.215

Lobeck, Anne. 1995. Ellipsis: Functional heads, licensing and identification. Oxford: Oxford University Press.

Montrul, Silvina. 2011. Introduction: The linguistic competence of heritage speakers. Studies in Second Language Acquisition, 33: 155-161. Retrieved December 21, 2020, from http://www.jstor.org/stable/44485999

Parodi, Teresa, Schwartz, Bonnie \& Clahsen, Harald. 2004. On the L2 acquisition of the morphosyntax of German nominals. Linguistics 42: 669-705. https://doi.org/10.1515/ling.2004.022. 
Perez-Cortes, Silvia, Putnam, Michael \& Sánchez, Liliana. 2019. Differential access: Asymmetries in accessing features and building representations in heritage language grammars. Languages. 4:81. https://doi.org/10.3390/languages4040081

Perez Leroux, Ana Teresa, Tough, Alexander, Pettibone, Erin \& Chen, Crystal. 2020. Los adjetivos relacionales cercanos: Corpus evidence for adjective ordering restrictions in Spanish. Conference presentation. Linguistic Symposium on Romance Languages 50.

Picallo, M. Carme. 2012. The Structure of the Noun Phrase. In J.I. Hualde, A. Olarrea \& E. O'Rourke (eds.) Blackwell handbook of Hispanic linguistics 263-384. Hoboken: Wiley. https://doi.org/10.1002/9781118228098.ch14

Pollock, Jean-Yves. 1989. Verb movement, universal grammar, and the structure of IP. Linguistic Inquiry, 20: 365-424.

Putnam, Michael \& Sánchez, Liliana. 2013. What's so incomplete about incomplete acquisition? - A prolegomenon to modeling heritage language grammars. Linguistic Approaches to Bilingualism 3: 378-504. https://doi.org/10.1075/lab.3.4.04put

Rothman, Jason, Judy, Tiffany, Guijarro-Fuentes, Pedro \& Pires, Acrisio. 2010. On the (un)-ambiguity of adjectival modification in Spanish determiner phrases: Informing debates on the mental representations of L2 Syntax. Studies in Second Language Acquisition 32: 47-77. https://doi.org/10.1017/s0272263109990258

Saab, Andrés. 2010. (Im)possible deletions in the Spanish DP. Iberia 2: 45-83.

Sánchez, Liliana. 1996. Syntactic Structures in Nominals: A Comparative Study of Spanish and Southern Quechua. Ph. D. dissertation, University of Southern California, Los Angeles.

Sánchez, Liliana. 2020. Adjetivos atributivos postnominales y estructuras predicativas / Postnominal attributive adjectives and predicate structures. Cuadernos de la Alfal. 12(2): 535-551

Ticio, Emma. 2010. Locality domains in the Spanish determiner phrase. London/New York: Springer. https://doi.org/10.1007/978-90-481-3398-7

Ticio, Emma. 2016. Nominal ellipsis as a collaborative effort. Borealis (Troms $\varnothing$ ), 5: 221. https://doi.org/10.7557/1.5.2.3130

Valdés, Guadalupe. 2000. Introduction. In N. Anderson (ed.), AATSP professional development series handbook for teachers K-16: Vol. 1. Spanish for native speakers. 1-20. New York: Harcourt.

Wiener, Seth \& Tokowicz, Natasha. 2019. Language proficiency is only part of the story: Lexical access in heritage and non-heritage bilinguals. Second Language Research. 1-15. https://doi.org/10.1177/0267658319877666

Zagona, Karen. 2000. The syntax of Spanish. Cambridge: Cambridge University Press. 